\title{
A Methodology for Tracing Lived-in Urban Heritage based on GPS and Satellite Image Processing Technology
}

\author{
Rizvi Noordeen, Dilmini Dissanayake, S.N Weerasinghe
}

\begin{abstract}
The process of urbanization and urban development in cities at an alarming rate pose numerous challenges for preservation and conservation of lived-in urban heritage therein. With the increasing demand for land and the resultant emphasis given to direct economic value of urban land, the significance of urban history and heritage in cities is underrated in the process of urban development. However, the aesthetic, cultural and heritage value they bring into cities are enormous and crucial for the sustenance of a city in terms of its history, image and identity. It has been a challenging task for urban Engineers, Architects and policy makers to trace historical monuments and help them preserve in cities. In this backdrop, this study intends to introduce a technology driven methodology to investigate on disappearing urban heritage and help to trace its original form and structure so that future preservation strategies could be implemented based on the same. For this purpose, we studied the remains of the $15^{\text {th }}$ Century Citadel Ramparts of the Kotte Kingdom in the suburban Colombo, using Magellan Meridian GPS technology, ArcGIS ArcMap software and satellite image processing techniques. The results show that this methodology is appropriate, with certain limitations, in tracing the original form and structure of the historic Citadel Rampart in historic Kotte Kingdom in Colombo. In this paper, we discuss the systematic approach we adopted and the data processing techniques we used in our study.
\end{abstract}

Keywords: Geo-reference, GIS, Heritage preservation, Meridian GPS technology, Satellite image, Tracing methodology

\section{INTRODUCTION}

$\mathrm{I}_{\mathrm{t}}$ is important to understand the significance of preserving cultural and heritage buildings and structures in cities. However, the rapid urbanization and the resultant acute demand for urban lands lead to threaten the existence and preservation of such cultural heritage in cities. Whether it is tangible or intangible, heritage is a testament to human creativity and it contributes to create an image and identity to places and people in cities [1]. Further, such heritage helps to revive local cultural values and develop national creativity and thereby leads to what Ismagilova, et.al (2015) call "cultural lifting" of the citizens [2]. It is generally a less troubling task, despite the challenges, to preserve cultural heritage in an urban environment when they are tangible and physically seen in the environment. However, when there is little or no physical evidence/structure existing, the task of its

Revised Manuscript Received on January 2, 2020.

* Correspondence Author

Rizvi Noordeen*, Department of Town and Country Planning, University of Moratuwa, Moratuwa, Sri Lanka. Email: nmrizvi@uom.lk

Dilmini Dissanayake, Department of Town and Country Planning, University of Moratuwa, Moratuwa, Sri Lanka. Email: dilminid@yahoo.com

S.N Weerasinghe, Department of Natural Sciences, Manchester Metropolitan University, UK . Email: sandaru.weerasinghe@gmail.com preservation is even more challenging for they receive less attention. Therefore, such cultural heritage in cities face threats and they are easily subjected to disappearance or negligence even though they possess higher cultural value and attribute longer history. Hence, it is important to trace the physical structures (existing and probable) based on the existing evidences (or leftovers).

There are various techniques used to trace the probable physical appearance and visual qualities of heritage. For example, rectified photography methods and photogrammetric pairing techniques are used to capture realistic visual record of historical structures/buildings [3]. Further metrological and town planning analysis, introduced by Conzen are also useful to determine the probable structures based on reconstruction of the historic urban morphology. However, such attempts were not able to produce high quality and appropriate results due to its lack of accuracy in predicting structures and higher subjectivity [4]. Therefore, there is a need felt to incorporate advance technology in tracing urban history and morphology. This started with the application of Computer-Aided Design (CAD) for reconstruction of heritage and to trace its architectural and visual qualities. Further advancement of the technology with the popularity of GIS software and image processing techniques enabled a more advanced path to document urban heritage. Yet, accuracy remained a key factor leading to question the application of such technology and techniques.

In the above backdrop, in this study we aimed at further improving the application of technology by introducing a new methodology for incorporating Magellan Meridian GPS technology to trace the probable structure of an urban heritage and prepare documentation that is more accurate. For this purpose, we selected to study the remains of the lived-in urban monument, namely the $15^{\text {th }}$ Century Citadel Ramparts of the Sri Jayawardhanapura Kotte Kingdom in the suburb of Colombo.

Sri Jayawardhanapura Kotte, one of the fastest growing suburbs of Colombo is also one of the last strongholds of Sri Lanka's illustrious history. Due to the on-going, fast paced physical and infrastructure development in Sri Jayawardhanapura Kotte, the traces of this once stronghold is fast disappearing in the name of progressive development. The city wall was built by the Chieftain Alagakkonara, also referred to as Nissanka Alagokkonara. A fortified Royal City, Kotte Kingdom was a resilient stronghold against enemies, local and foreign. It was the seat of rule of the entire island under the glorious times King Parakramabhahu V during the early part of the 14 th century. 
The Kabook city wall that once withheld the invading forces is impacted by today's changing land uses in the area. Even though there are civil organizations that voice concerns on the conservation of this edifice, the rapid urbanization and the demand for land for development sets back conservation efforts, from any progress. The main reason for this situation is the non-availability of reliable information for the continuous trace of this monument on ground, and a scientific assessment of the actual impact of regaining the historic trace for conservation. In the proceeding sections, we discuss our systematic approach and the new methodology adapted to trace and document the Citadel Rampart of Kotte.

\section{RESEARCH METHODOLOGY}

Below Fig. 1 provides the summary of the research approach used in our study.

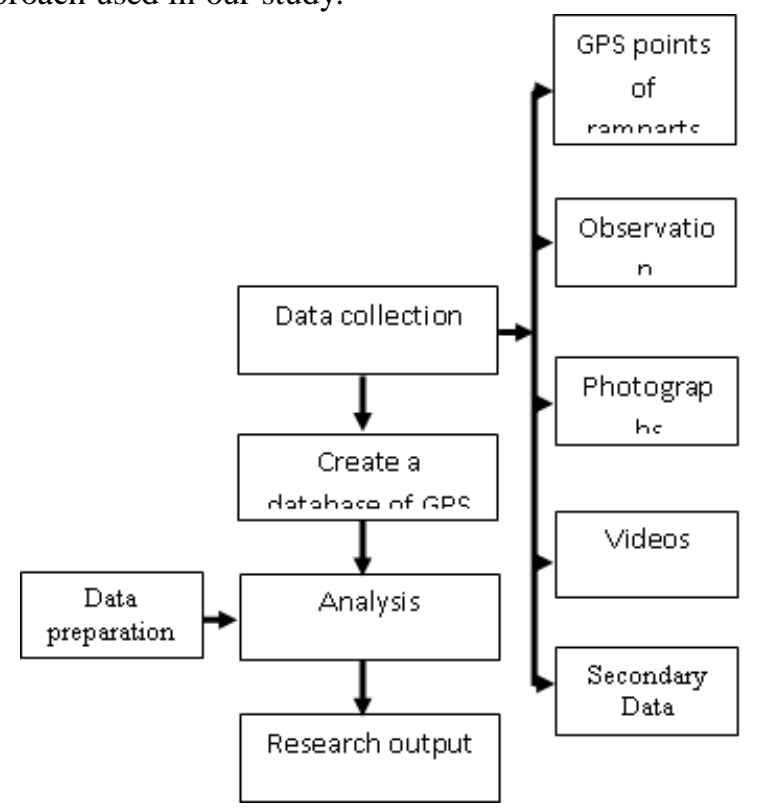

Fig. 1. Methodological framework for tracing the form and structure of the Citadel Ramparts of Kotte

\section{METHODOLOGY ADOPTED FOR TRACING THE CITADEL RAMPART}

In this section, we explain the detail methodology used in our study, in step-by-step, to derive the final map of Citadel Rampart and its full coverage using Magellan Meridian GPS.

\section{A. Marking of GPS points using Magellan Meridian GPS Unit}

The Magellan Meridian Color is the top of the Meridian line of GPS receivers. It comprises an outdoor viewable LCD screen with sixteen colour codes. This tool also includes pre-programmed map which contains major land-use details such as different categories of roads, railways, water bodies, administrative boundaries, parks, and other major infrastructures.

There are nine navigation options in the Meridian Color namely, Large data, Road, Position Screens, Speedometer, Map, Data, Compass, Data, and a Satellite Status screen. The Meridian Color is relatively easy to use for it comprises buttons that are larger in size compared to those in normal GPS receivers and that the screen is larger. The TTFF for cold starts are around 32 seconds. The estimated position error is generally between forty to sixty feet as long as it does not receive WAAS. As per the specifications, there is less than 10 feet WAAS accuracy. Marking and naming waypoints is the most essential task for which there are 42 different options provided to represent waypoints in Meridian Color, which is very useful.

A track Kit, a mobile GPS Tracking Service, was used which allowed us to record, upload, edit and share GPS tracks as we moved along the rampart. Information on Sun/Moon info, Twilights, raise/set times, countdown timers and the weather also were recorded. The data was used to cross-check the Magellan Meridian GPS as well as to keep a record of the walking tracks. It also was convenient since the tracks were directly uploaded to Google Earth via the app web link (see Fig. 2).

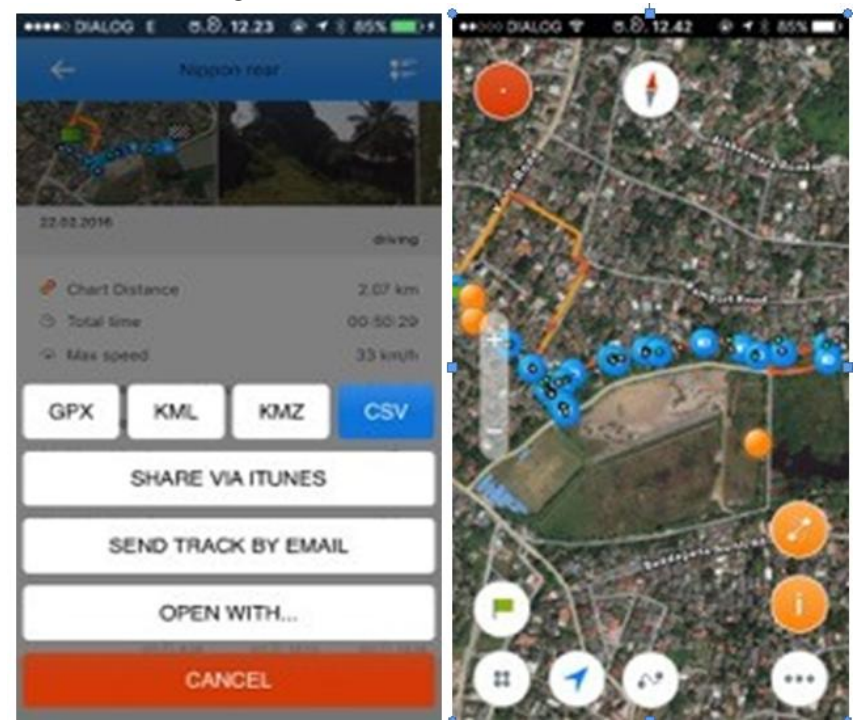

Fig. 2. Illustration of data recorded using track kit on a smart phone

\section{B. Saving a waypoint}

The next step was to save waypoints. A waypoint means a position on the globe saved in memory. Marking means the act of saving the waypoint when using Meridian Color. There are a number of methods to do marking with the use of Meridian GPS. The most common and easiest method is to save a current position and entering the matching coordinates of the same. Alternatively, we could also save the position of the cursor while viewing the map screen. These saved waypoints can later be used to generate followed routes or route maps or as the destination of a GOTO. (A GOTO is a single leg route that is defined as a route from a person's present position to any waypoint).

\section{Data preparation for analysis}

Prior to analyzing data obtained by the Magellan Meridian GPS, it was required to convert data into .shp (shape files) and gpx (the GPS Exchange Format) files, in order to load them in ArcMap application. In the process of data preparation for analysis, OziExplorer application was used for all types of data conversions and they were Waypoints to 
ESRI Shapefile, Waypoints to GPX and Waypoints to KML. Then we transformed the GPS data from the Magellan Meridian GPS to Computer and converted them to analyzable data formats, using below steps as shown in Table- 1.

Table- I: Data preparation steps and processes for analysis

\begin{tabular}{|c|l|}
\hline Step & \multicolumn{1}{|c|}{ Process } \\
\hline 01 & $\begin{array}{l}\text { After installing the OziExplorer.exe (setup file), } \\
\text { open the application and OziExplorer }\end{array}$ \\
\hline 02 & $\begin{array}{l}\text { Open a blank map (Map - Blank Map - Auto Scale) } \\
\text { in order to load the waypoints obtained by the } \\
\text { Magellan Meridian GPS on to OziExplorer } \\
\text { application. Transferring of waypoints on to the } \\
\text { blank map enabled us with data conversions. }\end{array}$ \\
\hline 03 & $\begin{array}{l}\text { After opening a blank map, we can input waypoints } \\
\text { from the GPS device to OziExplorer. }\end{array}$ \\
\hline 04 & $\begin{array}{l}\text { Upon the completion of data transferring process, } \\
\text { the waypoints are displayed on the blank map along } \\
\text { with their labels and coordinates. These waypoints } \\
\text { are now in a position for preparation and } \\
\text { conversion to analyzable data formats. }\end{array}$ \\
\hline 05 & $\begin{array}{l}\text { Imported waypoints were saved as KML for } \\
\text { Geo-referencing. }\end{array}$ \\
\hline
\end{tabular}

\section{Exporting to ArcGIS ArcMap for simulations}

After following the data preparation and conversion process as explained above, we exported ESRI shape files, GPX files and KML files that could be analyzed using spatial mapping applications such as ESRI ArcGIS: ArcMap and Quantum GIS (QGIS). In this case, we used ArcMap 10.2 and ArcMap 10.1 for spatial analysis of obtained data.

For detailed mapping, digitizing and analysis, following data inputs were used along with waypoints obtained by Magellan Meridian GPS:

- ESRI shapefiles of Sri Jayawardhanapura Kotte Municipal Council area - obtained from the Survey Department of Sri Lanka.

- Aerial photographs of the study area of 1956, 1972, 1982, 1999 and 2007 - obtained from the Survey Department of Sri Lanka.

- Google Earth images of the study area of 2016 obtained from Google Earth.

\section{E. Data preparation in ArcMap and analysis}

Prior to importing the converted waypoints to ESRI ArcMap 10.2 and 10.1, a certain process for preparation of data layers, aerial photographs and Google Earth satellite images had to be followed to ensure the location accuracy in terms of their actual coordinates. This had to be done in order to ensure the accurate overlapping of all data layers which was the main requirement for analysis of the study. The steps involved in this process of data preparation in ESRI ArcMap were as given in Table- II below. These steps could be performed in any order, as they are independent from each other; but it was necessary to complete all these steps in order to carry out a detailed analysis.
Table- II: The process of data analysis

\begin{tabular}{|c|l|}
\hline Step & \multicolumn{1}{|c|}{ Process } \\
\hline 01 & $\begin{array}{l}\text { Geo- referencing of the present i.e. 2016 Google Earth Satellite } \\
\text { Image with spatial data layers obtained from the Survey } \\
\text { Department of Sri Lanka. }\end{array}$ \\
\hline 02 & $\begin{array}{l}\text { Geo-referencing of the 1956, 1972, 1982, 1999 and 2007 aerial } \\
\text { photographs of the study area, which were obtained from the } \\
\text { Survey Department of Sri Lanka. Aerial photograph of 2007 was } \\
\text { geo-referenced with the 2016 satellite image, using "The } \\
\text { Parliament Premises" as the known ground feature. } \\
\text { Then, the rest of the aerial photographs were geo-referenced in } \\
\text { the reverse chronological order, following the same process as } \\
\text { mentioned in Step 01. }\end{array}$ \\
\hline 03 & $\begin{array}{l}\text { Overlaying of converted waypoints of ramparts with the spatial } \\
\text { data layers, the present satellite image and aerial photographs of } \\
\text { 05 decades. }\end{array}$ \\
\hline
\end{tabular}

\section{RESULTS}

Based on the above methodology, and the steps followed, we derived existing and probable citadel ramparts of Kotte with dimensions in $\mathrm{km}$ distance highlighting both existing and probable ramparts along with the land use of 2016 as shown in Fig. 5. Fig. 3 to 4 illustrate the geo-referenced aerial photographs with the overlaid actual coordinate waypoints obtained using the GPS.

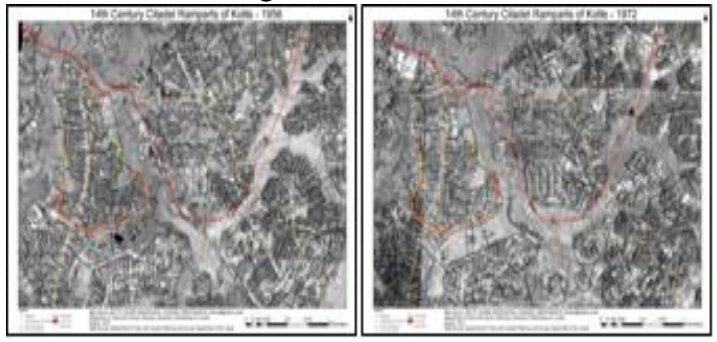

Fig. 3. Aerial photographs of 1956 (Left) and 1972 (Right) of Kotte highlighting the existing rampart of the Citadel and land use

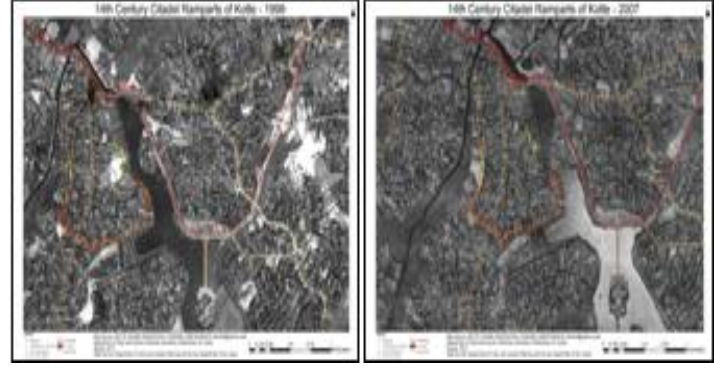

Fig. 4. Aerial photographs of 1999 (Left) and 2007 (Right) of Kotte highlighting the existing rampart of the Citadel and land use

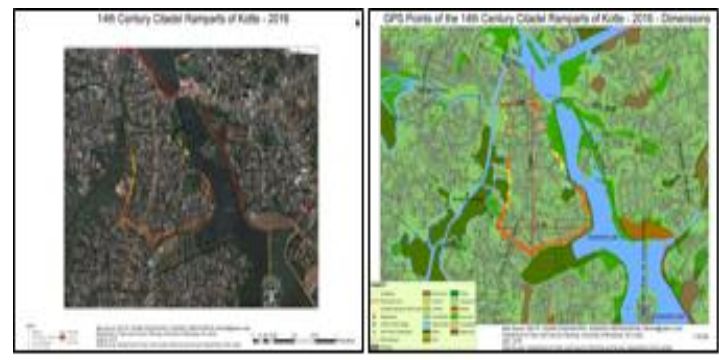

Fig. 5. Aerial photographs of 2016 (Left) exisitng and probable ramparts of Kotte with dimensions in $\mathrm{km}$ (Right) with 2016 land use 


\section{CONCLUSION}

Traditional data documentation and presentation involved the use of paper based formats. Nevertheless, such techniques are time consuming and hinders the updating and management of large quantities of spatial data. This flaw can be overcome by employing GIS methods in the documentation process [5]. The preservation and conservation of the cultural heritage as a whole requires a dynamic and state-of-the-art approach based on new forms of data and methods. his can be done not only through implementing conservation projects, but also through the documentation of such heritage in the past, present and the future through the application of Geographical Information Science (GIScience) as well as other novel methods [6].

As stated in the methodology section, applying GIScience in the work of Kotte citadel ramparts had an immense impact and provides a great opportunity in documenting the history of such a unique monument. This also ensures that the relevant data and information were collected and archived for future studies too. Such GIS database can play a critical role on the planning processes of cities and heritages [7]. The information documented and integrated on this study responds to a pre-determined lack of baseline data that is required for the adequate justification of preservation, conservation and management strategies.

The methodology employed in documenting the Kotte citadel ramparts is an example of building up a spatial database for documentation of lived-in urban heritage along with a participatory approach with the involvement of the community and secondary data from relevant institutions. A well-integrated spatial database of the Kotte citadel ramparts, as the final result, can represent a reinforced and a more informed decision-making process. This methodology has the potential to advance the planning processes as it provides a more practical methodology to determine, capture, and document historic monuments in an urban setting.

\section{ACKNOWLEDGMENT}

Authors would like to acknowledge the Senate Research Committee (SRC) Grant, University of Moratuwa, Moratuwa, Sri Lanka for funding this research.

\section{REFERENCES}

1. J. Portolés, "Cultural Heritage and Sustainable Cities. Key Themes and Examples in European Cities," UCLG Committee on Culture Reports. (2018)

2. G. Ismagilova, L. Safiullin, I. Gafurov, Using historical heritage as a factor in tourism development, Social and Behavioral Sciences, vol. 188, pp. 157 -162 (2015)

3. L.Khirfan, World heritage, urban design and tourism: three cities in the Middle East, Routledge, New York, (2016)

4. E. Koster, Urban Morphology and computers. Urban morphology 2, pp. 3 -10 (1998)

5. K. Shah, "Documentation and Cultural Heritage Inventories - Case of the Historic City of Ahmadabad." ISPRS Annals of Photogrammetry, Remote Sensing and Spatial Information Sciences, II-5/W3(5) pp. 271-278 (2015)

6. B. Husseini and Z. Bali, Documentation, using GIS techniques in conservation of a World Heritage Site, a case study of "The Old City of Jerusalem".' The International Archives of the Photogrammetry, Remote Sensing and Spatial Information Sciences, XL-5-W7 pp. 229-234 (2015)

7. O. Vileikis, E. Carrillo, S. Allayarov, and A. Feyzulayev, "Documentation for preservation: methodology and a GIS database of three world heritage cities in uzbekistan," ISPRS Annals of Photogrammetry, Remote Sensing and Spatial Information Sciences, IV-2/W2 pp. 311-318 (2017)

\section{AUTHORS PROFILE}

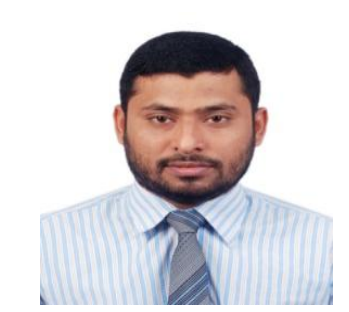

Rizvi Noordeen: B.Sc. (Hons) (Town \& Country Planning); PhD (UK); Chartered Town Planner (Reading). Dr. Rizvi is working as a Senior Lecturer at the Department of Town \& Country Planning, University of Moratuwa, Sr Lanka. He is also the Director of undergraduate studies of the Faculty of Architecture at the University of Moratuwa. His research works are focused on housing and conflicts, socio-spatial relations and multi-cultural studies.

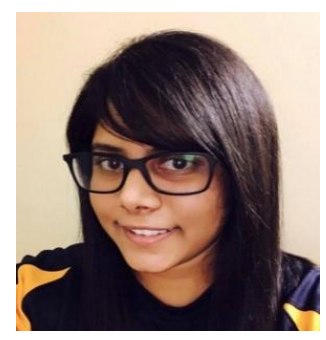

Sandaru N. Weerasinghe: B.Sc. (Hons) (Town \& Country Planning); MSc (Geographical Information Science) UK. Miss Weerasinghe is a doctoral student at the Manchester Metropolitan University, UK. She holds research concerns in the interrogation of fear of crime and healthy cities. In particular, she is interested in the application of Geographical Information Science and advanced quantitative methodologies to investigate people's perceptions of urban environments. 